EUROPEAN ORGANIZATION FOR NUCLEAR RESEARCH

European Laboratory for Particle Physics

Large Hadron Collider Project

LHC Project Report 131

\title{
High Current Diffusion Type Diodes at Cryogenic Temperatures for the LHC Superconducting Magnet Protection
}

\author{
L. Coull, R. Denz, D. Hagedorn
}

\begin{abstract}
High-current by-pass diodes are required for the protection of the superconducting magnets for the Large Hadron Collider LHC at CERN. These diodes are at liquid helium temperature and will be exposed to irradiation. With the re-location of the bypass diodes for the main dipoles underneath the iron yoke and of those for the quadrupoles at the bottom of the cryostat the new estimations for the irradiation dose amounts to about 30 Gy and a neutron fluence of about $1.5 \times 10^{11} \mathrm{n} / \mathrm{cm}^{2}$ for the dipole diodes and about 100 Gy and $5 \times 10^{11} \mathrm{n} / \mathrm{cm}^{2}$ for the quadrupole diodes during 10 years. These relatively low doses may allow the use of diffusion type diodes instead of epitaxial diodes. The electrical characteristics of several diodes were measured at temperatures in the range between $1.8 \mathrm{~K}$ and $300 \mathrm{~K}$. Diffusion type diodes from three manufacturers were submitted to high current endurance tests in liquid helium. Electrical characteristics and temperatures were measured versus time and showed acceptable results. First irradiation tests show that modified diffusion diodes can be used at least for the dipole by-pass.
\end{abstract}

\section{LHC-ICP}

CEC/ICMC 97 in Portland/Oregon/USA

\author{
Administrative Secretariat \\ LHC Division \\ CERN \\ CH-1211 Geneva 23 \\ Switzerland
}

Geneva, 18 August 1997 


\title{
HIGH CURRENT DIFFUSION TYPE DIODES AT CRYOGENIC TEMPERATURES FOR THE LHC SUPERCONDUCTING MAGNET PROTECTION
}

\author{
L. Coull, R. Denz, D. Hagedorn
}

CERN, CH-1211 Geneva 23, Switzerland

\begin{abstract}
High-current by-pass diodes are required for the protection of the superconducting magnets for the Large Hadron Collider LHC at CERN. These diodes are at liquid helium temperature and will be exposed to irradiation. With the re-location of the bypass diodes for the main dipoles underneath the iron yoke and of those for the quadrupoles at the bottom of the cryostat the new estimations for the irradiation dose amounts to about 30 Gy and a neutron fluence of about $1.5 \times 10^{11} \mathrm{n} / \mathrm{cm}^{2}$ for the dipole diodes and about 100 Gy and5 x $10^{11} \mathrm{n} / \mathrm{cm}^{2}$ for the quadrupole diodes during 10 years. These relatively low doses may allow the use of diffusion type diodes instead of epitaxial diodes. The electrical characteristics of several diodes were measured at temperatures in the range between $1.8 \mathrm{~K}$ and $300 \mathrm{~K}$. Diffusion type diodes from three manufacturers were submitted to high current endurance tests in liquid helium. Electrical characteristics and temperatures were measured versus time and showed acceptable results. First irradiation tests show that modified diffusion diodes can be used at least for the dipole by-pass.
\end{abstract}

\section{INTRODUCTION}

Originally it was foreseen to use epitaxial diodes for the high current by-pass at superfluid helium temperatures for the LHC superconducting magnets at CERN due to the relatively high estimated radiation dose of about $35 \mathrm{kGy}$ and neutron fluence of about $1.5 \times 10^{14} \mathrm{n} / \mathrm{cm}^{2}$ during 10 years [1].

With new detailed calculations for the irradiation dose and with the re-location of the by-pass diodes for the main dipoles underneath the iron yoke the most recent estimated 10-year doses and neutron fluences amount to about 30 Gy and $1.5 \times 10^{11}$ $\mathrm{n} / \mathrm{cm}^{2}$ for the dipole by-pass diode. The 10-year irradiation dose for the quadrupole diode, now located in the bottom of the cryostat, is estimated at about 100 Gy and a fluence of $5 \times 10^{11} \mathrm{n} / \mathrm{cm}^{2}$ [2]. These low doses may allow the use of diffusion type diodes instead of epitaxial diodes for the dipole by-pass. Epitaxial diodes may still be required.for some quadrupoles. 


\section{MAIN DIFFERENCES BETWEEN EPITAXIAL AND DIFFUSION TYPE DIODES}

\section{Main Differences in Processing}

Diodes Based on the Epitaxial Technology. To form a pn junction one starts to grow a thin $(<100 \mu \mathrm{m})$ single crystal layer of silicon on a n-doped Si substrate in a special atmosphere, whereby a silicon compound is reduced to pure silicon on the surface of the substrate. The epitaxy provides a silicon layer with a very low defect concentration and allows an abrupt change of the doping concentration. Unfortunately this technique is rather complicated and especially for wafers of large diameter not easy to control. The shaping of the pn junction is completed with the generation of a diffused $\mathrm{p}+$ layer on the epitaxial layer. This is normally done by the diode manufacturer, whereas the epitaxy, because of the inherent difficulties, is performed only by a few specialized silicon suppliers. Therefore small quantities of diodes are very expensive and have a long delivery time.

Diffusion type diodes. For power diodes of the diffusion type also a n-doped base material produced in conventional manner or neutron transmutation doped silicon is used. In order to obtain the very high doping concentrations, which are required for a power diode, a deep thermal diffusion of the dopant is performed on the silicon wafer. By this means the $n+$ zone of the diode is created. This high temperature process, which lasts several days, is carried out by the silicon supplier. For further processing the manufacturer grinds off one side of the silicon wafer. Subsequently the p+ layer is produced by ion implantation followed by a thermal diffusion step. Since the diffusion process leads to a thicker base width than the epitaxial technology, these diodes are in general less radiation hard.

\section{General Characteristics of the Tested Diodes}

The diodes from GEC-Plessey are standard high-voltage diodes from stock without any special passivation and locator for low temperature application, whereas the diffusion diode from WESTCODE is a specially developed thin wafer diode. The diodes from EUPEC are also specially developed. One diode is an epitaxial diode and the two diffusion type diodes, one doped with Gallium and the other doped with Boron, are made in deep diffusion technique applied to the basic material. With this kind of diffusion technique a thinner n-base region can be obtained resulting in a lower forward voltage drop and higher radiation resistance but at the expense of reverse voltage blocking capabilities. The edge passivation is similar to the passivation applied on the epitaxial diodes. The wafers of all tested diodes have an outer diameter of $75 \mathrm{~mm}$. Their general characteristics are shown in Table 1.

Table 1: General characteristics of the tested diodes

\begin{tabular}{llcccc}
\hline $\begin{array}{l}\text { Manu- } \\
\text { facturer }\end{array}$ & Diode Type & $\begin{array}{c}\text { Diode } \\
\text { Name }\end{array}$ & $\begin{array}{c}\text { Wafer } \\
\text { thickness } \\
{[\mu \mathrm{m}]}\end{array}$ & $\begin{array}{c}\text { Rated reverse } \\
\text { Voltage } \\
{[\mathrm{V}]}\end{array}$ & $\begin{array}{c}\text { Endurance } \\
\text { Test } \\
\text { at 4.2K }\end{array}$ \\
\hline EUPEC & Spec. develop. Epitaxial diode & E141 & 550 & 200 & yes \\
EUPEC & Spec. develop. Double Diff. (P, Ga) & EDD8 & 280 & 600 & yes \\
EUPEC & Spec. develop. Double Diff. (P, B) & E1024 & 280 & 600 & foreseen \\
GEC-Plessey & Standard Phase-Control, DS2101SY15 & M14 & 250 & 1500 & yes \\
Westcode & Stand. Rectif. Diode, SW14CXC32C & W046 & 234 & 1400 & yes \\
Westcode & Spec. develop. Rectif. Diode, & W003 & 184 & 500 & yes \\
& SW05CXC32C & & & & \\
\hline
\end{tabular}




\section{Main Electrical Differences}

Forward Characteristics. The main electrical characteristics for $22 \mu \mathrm{m}$ basewidth epitaxial diodes and various diffusion type diodes are given in Table 2 for different temperatures. The forward voltage measurement at a forward current $I_{f}=15$ $\mathrm{kA}$ was carried out with a $200 \mu$ s half sinusoidal current pulse [3].

In Table 2 the average differential resistance $r_{f}=\Delta \mathrm{U}_{\mathrm{f}} / \Delta \mathrm{I}_{\mathrm{f}}$ - derived from the forward current-voltage characteristics in Fig. 1 - in the current range $5 \mathrm{kA}<\mathrm{I}_{\mathrm{f}}<15 \mathrm{kA}$ is also presented. When lowering the temperature from $300 \mathrm{~K}$ down to $77 \mathrm{~K}$, epitaxial diodes show an almost pure voltage shift of about $0.3 \mathrm{~V}$ and almost no change in differential resistance, whereas diffusion type diodes show additionally to the 0.3 volt-shift a significant increase of differential resistance at $77 \mathrm{~K}$. At $4.2 \mathrm{~K}$ and $1.8 \mathrm{~K}$ the differential resistance is so high that at currents pulses above $1 \mathrm{kA}$ the temperature in the wafer increases significantly due to the measuring pulse itself and the $\mathrm{I}_{\mathrm{f}}-\mathrm{U}_{\mathrm{f}}$-characteristic is deformed. The forward voltages $\mathrm{U}_{\mathrm{f}}$ at $4.2 \mathrm{~K}$ and $1.8 \mathrm{~K}$ indicated in the table for the epitaxial diode and the diffusion diode from EUPEC are the values for higher temperatures than the initial temperature due to warm up during current pulsing.

In Fig. 1 the typical $I_{f}-U_{f}$-characteristics at $300 \mathrm{~K}$ and $77 \mathrm{~K}$ are shown for three diffusion diodes and a typical epitaxial diode for comparison. In Fig. 2 are the measured If- $\mathrm{Uf}_{\mathrm{f}}$-characteristics at $1.8 \mathrm{~K}$ and $4.2 \mathrm{~K}$ for two diffusion diodes and for an epitaxial diode given. The deformation of the curves ( shift towards lower forward voltage ) due to heating with increasing current is clearly visible.

Table 2: Measured electrical characteristics on epitaxial and diffusion type diodes at different temperatures

\begin{tabular}{|c|c|c|c|c|c|c|}
\hline $\begin{array}{l}\text { Electrical } \\
\text { parameter }\end{array}$ & $\begin{array}{c}\text { ( Initial ) } \\
\text { Temperature } \\
\mathrm{T}_{\mathrm{O}}[\mathrm{K}]\end{array}$ & 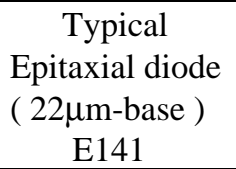 & $\begin{array}{c}\text { EUPEC } \\
\text { diffused } \\
\text { (Ga-doped) } \\
\text { EDD8 }\end{array}$ & $\begin{array}{l}\text { EUPEC } \\
\text { diffused } \\
\text { (B-doped) } \\
\text { E1024 }\end{array}$ & $\begin{array}{l}\text { GEC } \\
\text { diffused } \\
\text { M14 }\end{array}$ & $\begin{array}{l}\text { WEST- } \\
\text { CODE } \\
\text { W003 }\end{array}$ \\
\hline $\begin{array}{c}\mathrm{V}_{\text {to }}[\mathrm{V}] \\
10<\mathrm{dU} / \mathrm{d}+[\mathrm{V} / \mathrm{s}]>10^{4}\end{array}$ & $\begin{array}{l}4.2 \\
1 .\end{array}$ & $\begin{array}{l}1.2-1.5 \\
13-17\end{array}$ & $\begin{array}{l}12.8-16.5 \\
15.5-172\end{array}$ & $\begin{array}{l}6.4-8.8 \\
6.9-9.4\end{array}$ & $\begin{aligned} 7.0 & -8.0 \\
\sim & 86\end{aligned}$ & $\begin{array}{l}5.7-7.5 \\
59-7.9\end{array}$ \\
\hline $\begin{array}{c}\mathrm{U}_{\mathrm{f}} \\
\text { at } \\
\mathrm{I}_{\mathrm{f}}=15 \mathrm{kA}\end{array}$ & $\begin{array}{r}300 \\
77 \\
4.2 \\
1.8\end{array}$ & $\begin{array}{l}1.0 \\
1.25 \\
1.7 \\
1.8\end{array}$ & $\begin{array}{l}1.4 \\
2.5 \\
9.0 \\
* *\end{array}$ & $\begin{array}{c}1.08 \\
1.59 \\
4.15 \\
4.15\end{array}$ & $\begin{array}{l}1.2 \\
2.6 \\
* * \\
* *\end{array}$ & $\begin{array}{c}1.2 \\
2.2 \\
4.3 \\
4.3\end{array}$ \\
\hline $\begin{array}{c}\mathrm{U}_{\mathrm{r}-\max } \\
{[\mathrm{V}]}\end{array}$ & $\begin{array}{r}300 \\
77 \\
4.2 \\
1.8\end{array}$ & $\begin{array}{l}\sim 200 \\
\sim 150 \\
\sim 100 \\
\sim 100\end{array}$ & $\begin{aligned}> & 720 \\
> & 560 \\
\sim & 170 \\
& * *\end{aligned}$ & $\begin{array}{l}>500 \\
>370 \\
\sim 370 \\
\sim 370\end{array}$ & $\begin{aligned}> & 1100 \\
> & 1100 \\
\sim & 640 \\
& * *\end{aligned}$ & $\begin{array}{l}\sim 900 \\
\sim 900 \\
\sim 600 \\
\sim 300\end{array}$ \\
\hline $\begin{array}{l}\Delta \mathrm{U}_{\mathrm{f}} / \Delta \mathrm{I}_{\mathrm{f}}[\mu \Omega] \\
\Delta \mathrm{U}_{\mathrm{f}} / \Delta \mathrm{I}_{\mathrm{f}}[\mu \Omega] \\
\Delta \mathrm{U}_{\mathrm{f}} / \Delta \mathrm{I}_{\mathrm{f}}[\mu \Omega] \\
\Delta \mathrm{U}_{\mathrm{f}} / \Delta \mathrm{I}_{\mathrm{f}}[\mu \Omega]\end{array}$ & $\begin{array}{r}300 \\
77 \\
4.2 \\
1.8\end{array}$ & $\begin{aligned} \sim & 14 \\
\sim & 15 \\
& * \\
& *\end{aligned}$ & $\begin{array}{l}\sim 35 \\
\sim 95 \\
* \\
*\end{array}$ & $\begin{array}{l}\sim 16 \\
\sim 31 \\
* \\
*\end{array}$ & $\begin{array}{r}\sim 21 \\
\sim 85 \\
\quad * \\
\quad *\end{array}$ & $\begin{array}{l}19 \\
70 \\
* \\
*\end{array}$ \\
\hline
\end{tabular}

$*$ not measurable ** not measured 


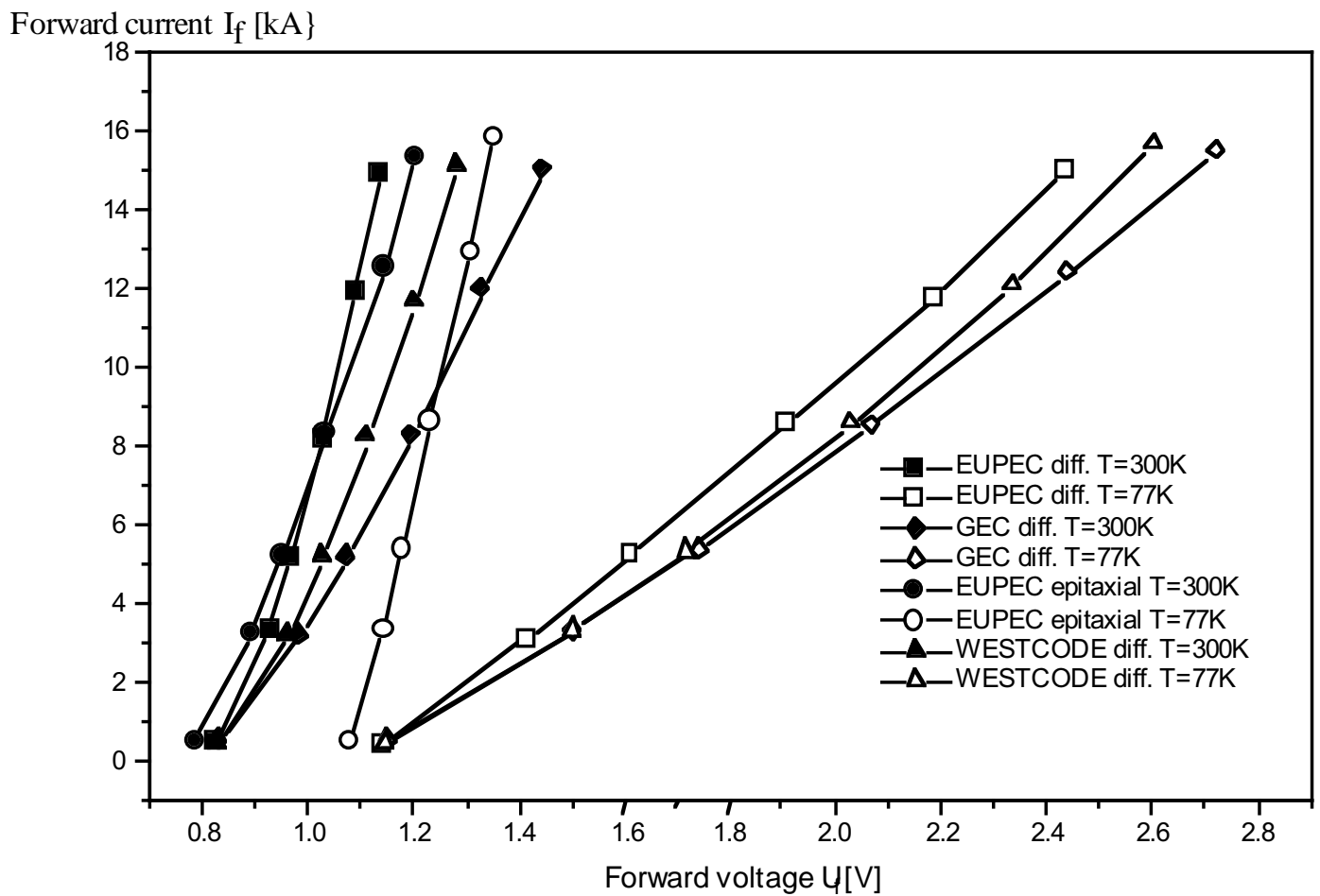

Figure 1. Measured forward current-voltage characteristics at $77 \mathrm{~K}$ and $300 \mathrm{~K}$ on three diffusion diodes and one epitaxial diode for comparison.

Reverse Voltage Characteristics. The reverse voltage was measured before the endurance tests and after each run of endurance test. No significant changes were observed. Typical values are given in Table 2.

Forward current $\mathrm{I}_{\mathrm{f}}[\mathrm{kA}\}$

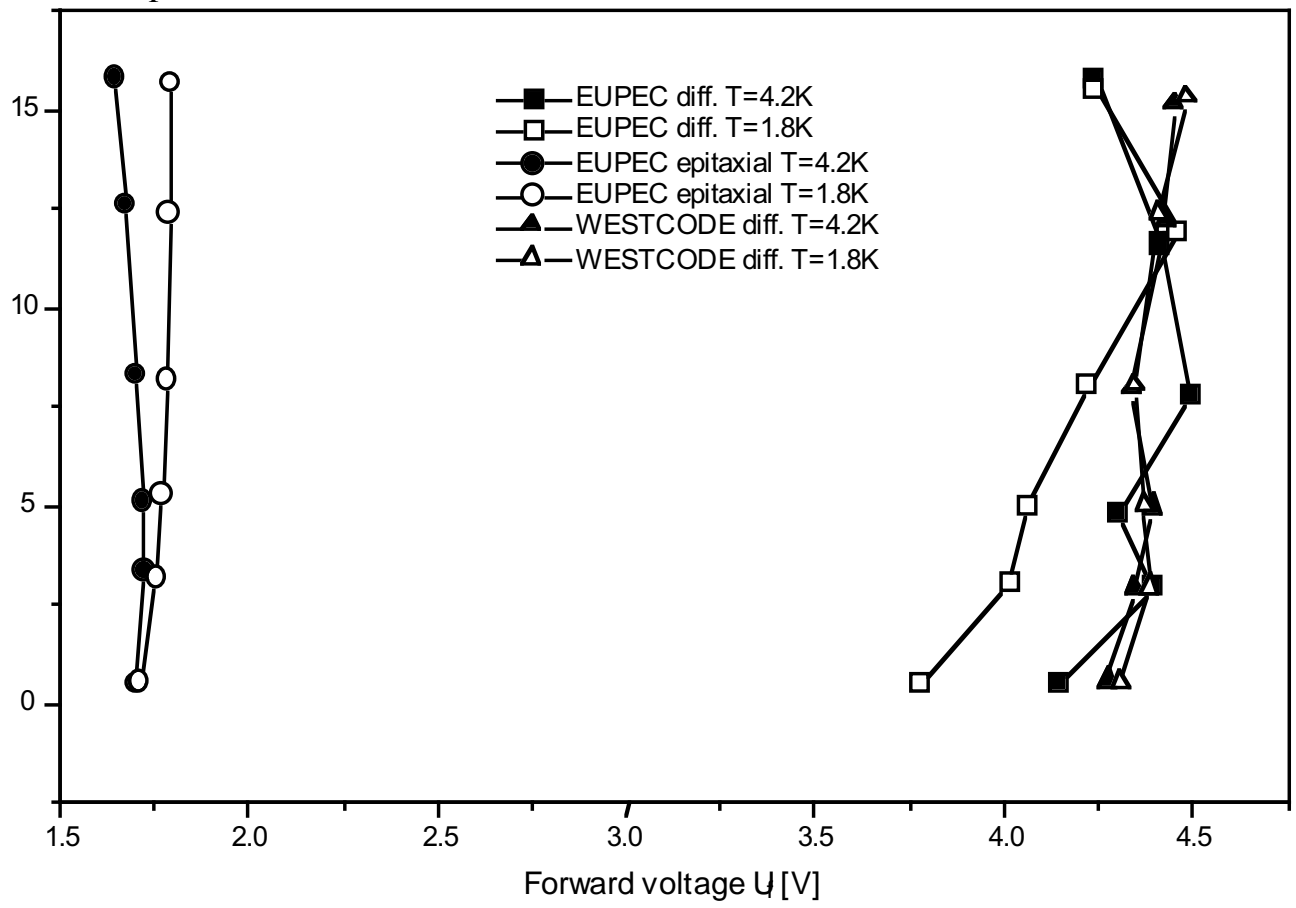

Figure 2. Forward Current-Voltage characteristic at $1.8 \mathrm{~K}$ and $4.2 \mathrm{~K}$ initial temperature for two diffusion type diodes and one epitaxial diode.

During the reverse voltage tests at $1.8 \mathrm{~K}$ and $4.2 \mathrm{~K}$ on the double diffusion diodes from EUPEC in current control the reverse voltage increased up to about $\mathrm{U}_{\mathrm{r}}=370 \mathrm{~V}$ as 
shown in Table 2. After exceeding a reverse current $\mathrm{I}_{\mathrm{r}}$ of about $50 \mu \mathrm{A}$ the reverse voltage of all double diffusion diodes from EUPEC dropped down to about $130 \mathrm{~V}$ up to reverse currents of about $1 \mathrm{~mA}$. After warm up to $300 \mathrm{~K}$ the reverse characteristics at $77 \mathrm{~K}$ and $300 \mathrm{~K}$ were found normal and unchanged. The same effect was observed on one of the diodes without passivation on the rim so that it cannot be attributed to the passivation. Some additional tests at several temperatures in the range between $4.2 \mathrm{~K}$ and $77 \mathrm{~K}$ lead to the conclusion, that the irreversible phenomenon starts below about $50 \mathrm{~K}$ and disappears at temperatures above $50 \mathrm{~K}$. The observed behaviour is probably due to the impact ionisation of frozen out impurities leading to a generation of current filaments inside the depletion layer . [4]

Turn-On Voltage Characteristics. Turn-on voltages have been measured at $1.8 \mathrm{~K}$ and $4.2 \mathrm{~K}$ at different voltage rise rates in the range $10 \mathrm{~V} / \mathrm{s}<\mathrm{dU} / \mathrm{dt}<10^{4} \mathrm{~V} / \mathrm{s}$ [5]. The results in Table 2 allow the following general interpretation: the turn-on voltage $\mathrm{V}_{\text {to }}$ increases with voltage rise rate $\mathrm{dU} / \mathrm{dt}$ and the $\mathrm{V}_{\text {to }}$ at $1.8 \mathrm{~K}$ is higher than at $4.2 \mathrm{~K}$. The lowest turn-on voltage for diffusion diodes is at least 3 times higher than for epitaxial diodes so that only one diffusion diode for the dipole by-pass needs to be foreseen instead of two epitaxial diodes in series.

An abnormality has been observed on diode M14 each time after cool down to $4.2 \mathrm{~K}$ and $1.8 \mathrm{~K}$ : a turn on voltage of about $\mathrm{V}_{\text {to }}=60 \mathrm{~V}$ has been measured during the first $\mathrm{V}_{\text {to }}$ measurement and this dropped down to reasonable values - as shown in Table 2 - during subsequent measurements. This effect of excessive $\mathrm{V}_{\text {to }}$ has already been observed on some of the HERA-diodes tested at $4.2 \mathrm{~K}$ at CERN, when a $\mathrm{V}_{\text {to }}$ of about $12 \mathrm{~V}$ instead of $4-5 \mathrm{~V}$ was measured. It seems to be a peculiarity of a few diodes of the diffusion type because it has never been observed on epitaxial diodes. This high $\mathrm{V}_{\text {to }}$ could be dangerous for a magnet in the LHC by-passed by such a diode since it will cause an additional delay before the diode is turned on.

\section{ENDURANCE TESTS}

\section{Test Conditions}

Diffusion type diodes from three manufacturers were submitted to endurance tests at liquid helium temperature similar to the procedure for epitaxial diodes [6]. Each diode was mounted under a force of about $44 \mathrm{kN}$ between two Copper disks of about 1600 $\mathrm{cm}^{3}$ volume each acting as heat sinks. Prior to mounting, the quality of the contact surfaces between the diode electrodes and the heatsinks were checked with Fuji-paper prints.

Due to the rather high turn-on voltage $\mathrm{V}_{\text {to }}$ of about $4-17 \mathrm{~V}$ for the diffusion type diodes compared to about $1.4-1.6 \mathrm{~V}$ for epitaxial diodes these diffusion diodes had to be tested individually in different runs ( power supply output voltage limitation ). A computer controlled power supply of $20 \mathrm{kA}, 20 \mathrm{~V}$ provided the required current pulse consisting of a fast ramp to the peak current $\mathrm{I}_{\mathrm{O}}$ within about $1 \mathrm{~s}$ and an exponential decay with the time constant of about $100 \mathrm{~s}$.

During each current cycle, the current, the diode voltage, the heat sink temperatures, and the contact voltages were monitored versus time. Current and diode voltage measurements were used to calculate the junction diode temperature [5]. The heat sink temperature was monitored via Pt-100 sensors. Each diode was submitted to several successive current pulse cycles. After each cycle the reverse current-voltage characteristics of the diodes were re-measured after cooling down to $4.2 \mathrm{~K}$. 


\section{Endurance Test Results}

Forward Voltages. The typical forward voltages of one epitaxial diode and three diffusion diodes during an endurance current cycle of $13 \mathrm{kA}$ peak are plotted versus time in Figure 3. The insert is a zoom of the beginning of the cycle and shows the forward voltage just before turn on. As the resolution in time is $100 \mathrm{~ms}$, the exact value of the turn-on voltage as shown in Table I is not always recorded. Immediately after this peak voltage, the forward voltage decreases rapidly within $10 \mathrm{~s}$ to about $1 \mathrm{~V}$ for the epitaxial diode and about $1.2 \mathrm{~V}$ for the diffusion diodes. Afterwards, up to 300 seconds, the average forward voltage is about $0.9 \mathrm{~V}$ for the epitaxial diode and about $1.1 \mathrm{~V}$ for the diffusion type diodes.

The high voltage of about 15 volt before turn on is typical for one of the firstly delivered diffusion diodes from EUPEC with Gallium doping. The later diffusion type diodes from EUPEC are high level Boron doped with a lower turn on voltage as shown in Table 1.

Wafer Temperatures. Figure 4 is a plot of the temperature of the diode junction itself versus time deduced from previous pulse current and voltage measurements. For all diffusion diodes, the maximum temperatures - reached after about 10-15 seconds - is between $300 \mathrm{~K}$ and $320 \mathrm{~K}$. The temperature rise up to about $440 \mathrm{~K}$ for the epitaxial diode is due to a smaller heat sink volume (copper) foreseen for an installation in the magnet string at CERN. The slightly lower peak temperature of the WESTCODE diode W046 can be attributed to the somewhat lower contact resistance between diode and heat sink which provides a better heat transfer to the heat sinks. The temperature decreases to about $200 \mathrm{~K}$ after 300 seconds. These wafer temperatures are only indicative, the two point calibration at $77 \mathrm{~K}$ and $300 \mathrm{~K}$ does not permit an absolute precision of better than about $\pm 20 \mathrm{~K}$.

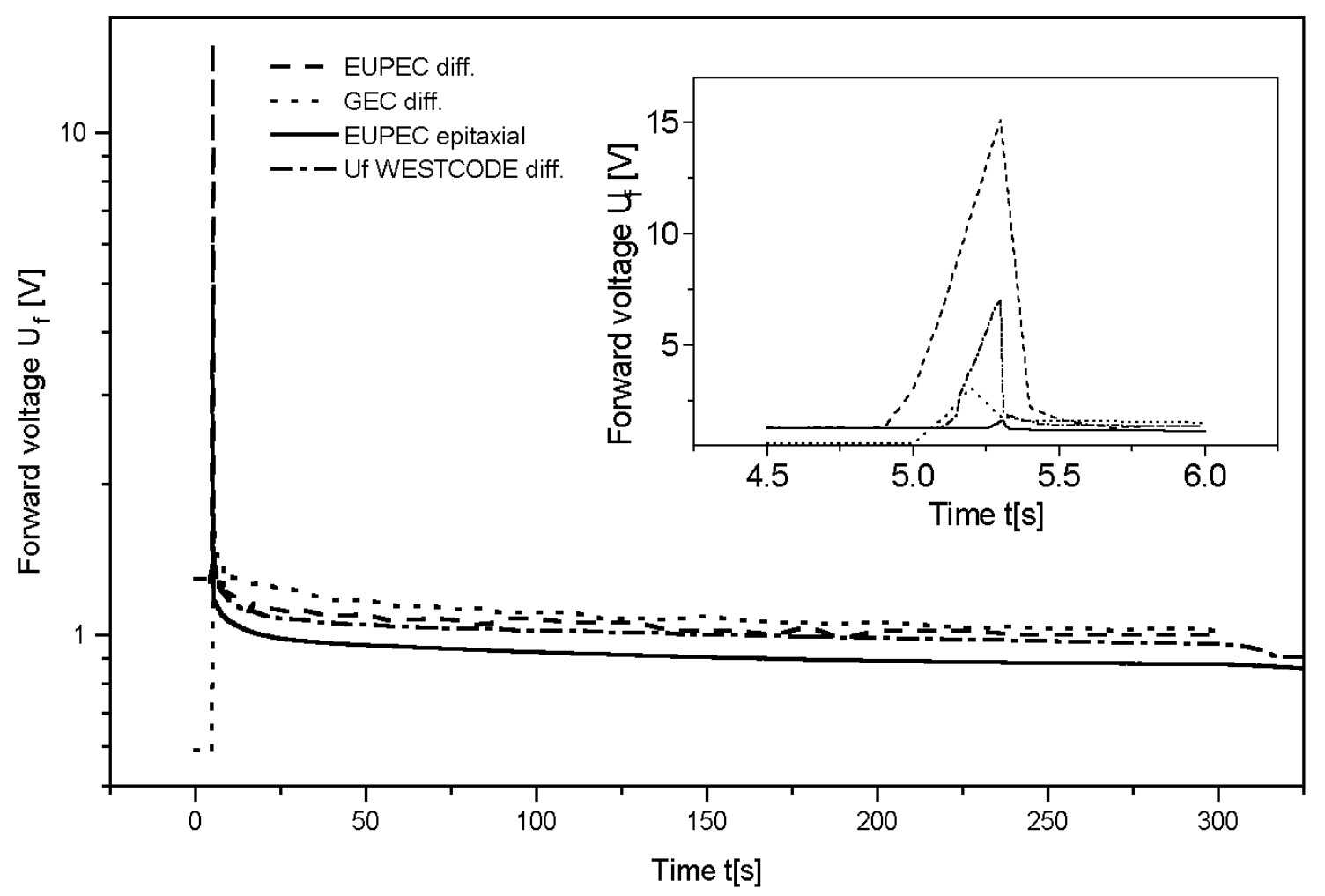

Figure 3. Forward voltages versus time of different types of diodes during an endurance test 


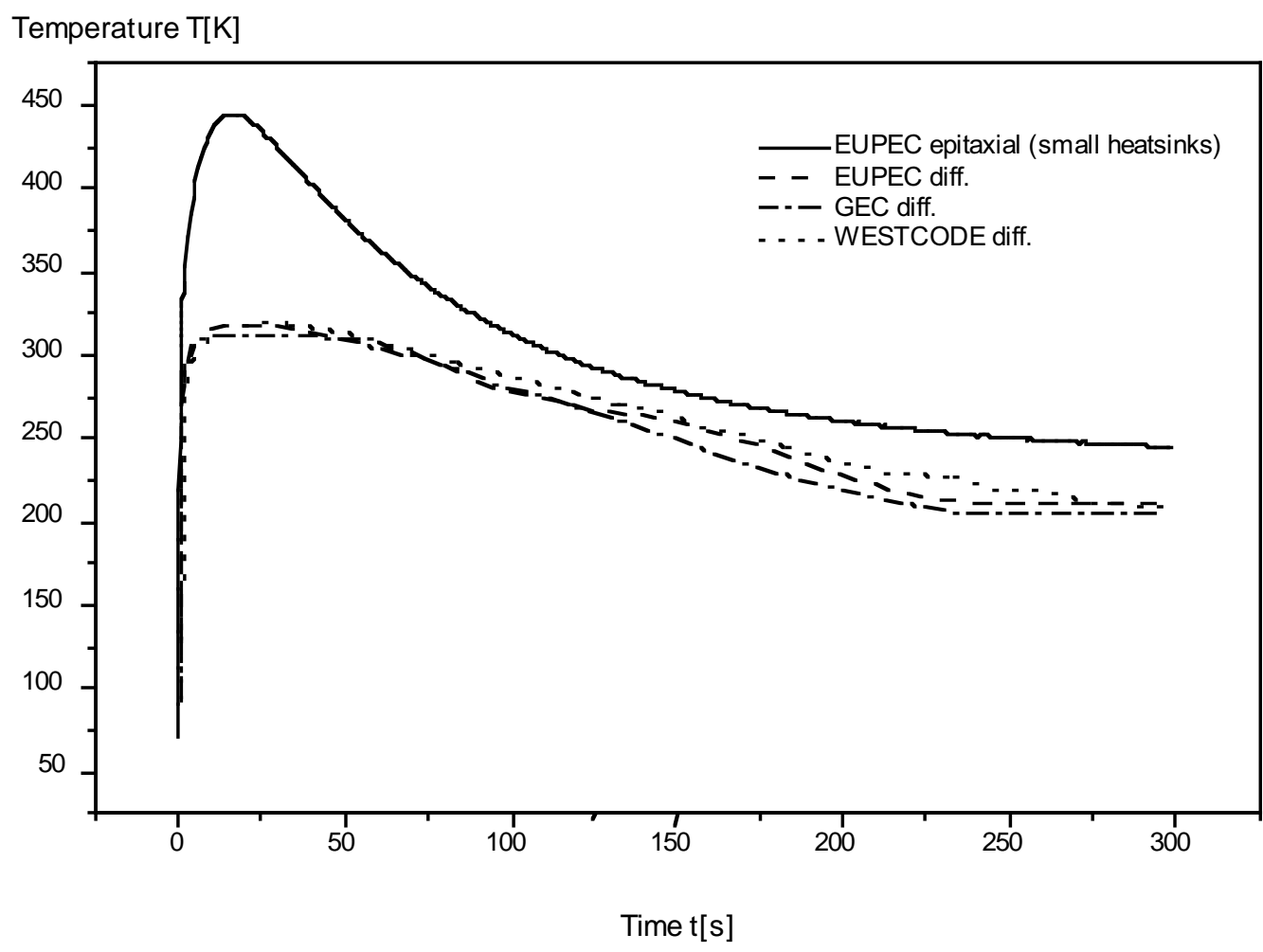

Figure 4. Wafer temperatures versus time of different types of diodes during an endurance test.

Heatsink Temperatures. For all diffusion diodes the maximum heat sink temperature stays below $200 \mathrm{~K}$ mainly due to the larger heatsink of about $1600 \mathrm{~cm}^{3}$ of copper on each side of the diode, whereas the maximum temperature of the smaller heat sinks of the epitaxial diode of about $900 \mathrm{~cm}^{3}$ reach about $220 \mathrm{~K}$ although the totally deposited energy is smaller than in all diffusion diodes. Using a larger heatsink volume also for the epitaxial diodes results in much lower temperatures for the wafer and the heat sinks [6].

Contact Resistances. The electrical contact resistance between heat sink and anode respectively cathode of each diode was continuously monitored versus time. Average electrical contact resistances in the range between $0.3 \mu \mathrm{m}$ and $4 \mu \mathrm{m}$ were measured. The lower the electrical contact resistance the lower was the temperature difference between wafer and heatsink indicating a faster heat diffusion from the wafer to the heatsinks. In general an average contact resistance value of a few $\mu \mathrm{W}$ is acceptable.

\section{PRELIMINARY RESULTS FROM IRRADIATION TESTS}

First results from irradiation tests at $77 \mathrm{~K}$ in an accelerator environment - just under way - show that the standard high-voltage diffusion diodes from GEC and WESTCODE are still too radiation sensitive, whereas the low voltage diodes from WESTCODE and especially the Boron -doped double diffusion diodes from EUPEC show sufficient radiation hardness up to a dose of about $300 \mathrm{~Gy}$ and fluences up to about $10^{12}$ neutrons $/ \mathrm{cm}^{2}$. A certain radiation hardness can be obtained only at the expense of lower reverse voltage. These irradiation test at $77 \mathrm{~K}$ in an accelerator environment will continue as well as irradiation tests at $4.2 \mathrm{~K}$ in a nuclear reactor [7]. 


\section{CONCLUSIONS AND FUTURE EXPERIMENTS}

The use of diffusion type diodes instead of epitaxial diodes for the high current bypass - at least across the dipole magnets - will result an a significant cost reduction, since only one diode per double aperture dipole is necessary and diffusion diodes are less expensive than epitaxial diodes. The maximum wafer and heat sink temperatures depend on the copper heatsink volume and can be kept below critical values.

Occasionally diffusion diodes show an abnormally high turn-on voltage at liquid helium temperatures. This will require systematic checking for elimination of those devices.

First irradiation results show that standard diffusion diodes are too radiation sensitive. Specially developed thin-wafer diffusion diodes are sufficiently radiation hard but at the cost of lower reverse voltage. The lower reverse voltage could be acceptable, at least for the quadrupole by-pass.

The following tests are required in order to validate completely the use of diffusion diodes for the high current by-pass in the LHC:

- irradiation and annealing of diode samples at $4.2 \mathrm{~K}$

- establishing optimum annealing procedures after irradiation at $4.2 \mathrm{~K}$

- over-irradiation of diode samples followed by endurance tests at $4.2 \mathrm{~K}$

- testing of a small series of diodes from each manufacturer ( up to now only a few prototypes have been tested ).

\section{ACKNOWLEDGEMENTS}

The authors would like to thank A. Gharib and O. Desebe for carefully carrying-out the measurements, J.M. Fraigne for the careful design of the sample holders, Mr. Rieubland and his team for their support during measurements at $1.8 \mathrm{~K}$, and L. Walckiers and his team for their support during endurance testing.

\section{REFERENCES}

1. L. Burnod,J. B. Jeanneret, and H. Schönbacher. Expected doses inside and around LHC dipoles, AC/DI/FA/ Note 93-06 (1993)

2. G. Stevenson, Private communication, 16.06.97

3. V. Berland, D. Hagedorn, A. Gharib, Power diodes submitted to radiation at $77 \mathrm{~K}$ in an accelerator environment - target T6 of TCC2 in the SPS -, CERN/LHC-ICP/VB 95-125, Internal note, July 1995.

4. R. E. Kunz, E. Schöll et al., Solid-State Electronics, Vol. 39, p.1155-1164, 1996

5. D. Hagedorn, W. Nägele, Quench protection diodes for the LHC at CERN, "Advances in Cryogenic Engineering (Materials) ", Vol.38, 1992

6. V. Berland, D.Hagedorn, A. Gharib, Comparison between two types of power diodes submitted to high current cycle endurance tests, CERN/LHC-ICP/VB 96-01, Internal Note April 1996

7. V. Berland, D. Hagedorn, H. Gerstenberg, Behaviour of the future LHC magnet protection diodes irradiated in a nuclear reactor at $4.6 \mathrm{~K}$ with intermediate annealing, RADiation Effects on Components and Systems conference (RADECS 95), Arcachon-France, September 1995. 